\title{
Are Hormonal Agents Better Than Chemo in Metastatic Castration-resistant Prostate Cancer?
}

\author{
(1) Serkan YILDIRIM, ${ }^{1}$ (1) Atike Pınar ERDOĞAN² \\ 'Department of Medical Oncology, Bitlis Tatvan Public Hospital, Bitlis-Turkey \\ ${ }^{2}$ Department of Medical Oncology, Manisa Celal Bayar University, Manisa-Turkey
}

\begin{abstract}
OBJECTIVE
In this study, we aim to determine which treatment is more appropriate in castration-resistant chemotherapy-naive patients. Therefore, docetaxel and agents active in the androgen pathway (abiraterone and enzalutamide) were compared retrospectively in patients progressing on androgen deprivation therapy.

\section{METHODS}

The study was designed as a retrospective and multicenter study. Patients from five centers in Turkey were included in the study. The primary endpoint of the study was overall survival (OS) and the secondary endpoint was progression-free survival.

\section{RESULTS}

Median OS of the docetaxel group was 18.66 months, it was 16.26 months in the hormonal treatment group. There was no statistically significant difference between the groups $(\mathrm{p}=0.311)$. Median progressionfree survival of the chemotherapy group was 5.6 months, while it was 9 months in the hormonal therapy group. There was statistically significant difference between the groups $(\mathrm{p}=0.024)$.
\end{abstract}

\section{CONCLUSION}

There was statistical difference in progression-free survival in favor of hormonal therapies in our study. The difference did not reflect on OS and there was no difference between hormonal therapies and docetaxel. Heterogeneity in the selection of patients is considered to lead to this result; however, larger randomized controlled studies are needed to determine the most appropriate treatment in these patients.

Keywords: Abiraterone; castration resistant; docetaxel; enzalutamide.

Copyright $\odot$ 2021, Turkish Society for Radiation Oncology

\section{Introduction}

Androgen deprivation therapy (ADT) alone or in combination with chemotherapy is usually the initial treatment of metastatic castration-sensitive prostate cancer. This treatment creates an objective tumor response in most patients and alleviates symptoms.[1] However, progression is inevitable in these patients and additional treatments are required. The disease is called castra- tion-resistant prostate cancer (CRPC) after developing resistance to ADT. Expected survival rate is low at this level of the disease and patients die substantially due to CRPC. [2,3] Therefore, various agents have been used to treat CRPC. Docetaxel is the first agent used following ADT in this regard. In a study, docetaxel provided overall survival (OS) in patients compared to mitoxantrone.[4] Other agents were used alone or in combination after above-mentioned success of docetaxel, but 
they were not effective.[5-14] Cabazitaxel was found to be effective in patients with CRPC just like docetaxel; however, it was used in post-docetaxel period as it was identified that there was no difference between cabazitaxel and docetaxel in a head-to-head study.[15]

Agents affecting the androgen pathway were also used in CRPC patients. Abiraterone which is an androgen synthesis inhibitor and enzalutamide which is an androgen receptor blocker were used in chemotherapy-naive CRPC patients. Abiraterone was superior to placebo in a study comparing abiraterone with placebo and contributed to both progression-free survival and OS.[16-18] Similarly, enzalutamide was compared with placebo in chemotherapy-naive CRPC patients and it also contributed to progression-free survival and OS.[19-21]

After developing castration resistance, patients have limited response to various treatments; therefore, treatments focused on castration-sensitive period. Chemotherapy and agents active in the androgen pathway are frequently used in combination with ADT in this period. Treatments combined with ADT have become the standard, especially in patients with high disease burden and high risk. However, ADT alone is frequently administered as the initial treatment in metastatic patients. There is no exact information about which treatment should be chosen in these patients after developing castration resistance.

In this study, we aim to determine which treatment is more appropriate in castration-resistant chemotherapy-naive patients. Therefore, docetaxel and agents active in the androgen pathway (abiraterone and enzalutamide) were compared retrospectively in patients progressing on ADT.

\section{Materials and Methods}

The study was designed as a retrospective and multicenter study. Patients from five centers in Turkey were included in the study. Files of the patients who applied to these centers between 2016 and 2020 were analyzed and the data were obtained. Inclusion criteria were age $>18$ years, having metastatic disease, being local treatment naive (surgery or radiotherapy), being chemotherapy naive, and progressing only on ADT. The patients were divided into two groups based on the treatments they received. The first group included those patients who received docetaxel (chemotherapy group). The second group included the patients who received enzalutamide or abiraterone (hormonal therapy group).
OS was defined as the time from the start of second line therapy to death or the last follow-up examination. Progression-free survival was defined as the time from the start of second-line therapy to the date of progression, death, or the last follow-up examination. Tumor progression was evaluated according to the RECIST criteria (only PSA elevation was not accepted as progressive disease). Moreover, following parameters which may affect the survival of the patients were analyzed in Cox regression model: Age (over 65 vs. under 65), location of metastasis (bone only vs. others), Gleason score (9-10 vs. $\leq 8)$, and disease burden (high volume vs. low volume-CHAARTED definition). The study was approved by the Manisa Celal Bayar University Faculty of Medicine Ethics Committee (No: 20.478.486, Date: 23/12/2020).

All analyses were performed using the SPSS statistical software program package (SPSS version 20.0 for Windows). The Chi-square test analyzed the differences in the clinical characteristics between the two groups. OS was calculated with the log-rank test. The Kaplan-Meier method was used to draw survival curves. The Cox proportional hazards regression model was used to determine statistically significant variables related to OS. Differences were assumed to be significant when $\mathrm{p}<0.05$ was considered.

\section{Results}

A total of 80 patients were included in the study. A total of 44 patients received docetaxel and 36 patients received hormonal therapy (abiraterone or enzalutamide). The mean age of patients in the chemotherapy group was 65.5 years (43-82), and it was 71.5 years in the hormonal therapy group (48-96). The mean followup duration was 20.4 months for chemotherapy group and 15.6 months for hormonal therapy group. When the distribution rates of age, location of metastasis, Gleason score, and disease burden parameters in the groups were analyzed, it was found that only patients over 65 years of age were statistically higher in the hormonal treatment group. The characteristics of the patients are shown in Table 1.

The effect of these four variables (age, location of metastasis, Gleason score, and disease burden) on the survival of all patients was also studied in in the multivariate analysis. Among these variables, only the Gleason score had a statistically significant effect on the survival $(\mathrm{p}=0.029)$ (Table 2$)$.

Median OS of the chemotherapy group was 18.66 months, it was 16.26 months in the hormonal treat- 


\begin{tabular}{|c|c|c|}
\hline Patients & $\begin{array}{l}\text { Docetaxel } \\
\qquad(n=44)\end{array}$ & $\begin{array}{c}\text { Enzalutamide } \\
\text { or abiraterone } \\
\qquad(n=36)\end{array}$ \\
\hline \multicolumn{3}{|l|}{ Age } \\
\hline$p=0.042$ & $65.5(43-82)$ & $71.5(48-96)$ \\
\hline \multicolumn{3}{|l|}{ Gleason 9-10 } \\
\hline$p=0.341$ & 24 & 17 \\
\hline \multicolumn{3}{|l|}{ Bone only disease } \\
\hline$p=0.499$ & 28 & 22 \\
\hline Visceral disease & 4 & 3 \\
\hline \multicolumn{3}{|l|}{ Volume (CHAARTED definition) } \\
\hline High volume & 15 & 8 \\
\hline $\begin{array}{l}\text { Low volume } \\
\mathrm{p}=0.179\end{array}$ & 29 & 28 \\
\hline Mean follow-up duration (month) & 20.4 & 15.6 \\
\hline
\end{tabular}

CHAARTED: Chemohormonal Therapy in Metastatic Hormone-Sensitive Prostate Cancer Study

Table 2 Cox regression

\begin{tabular}{lcc} 
All Patients & Sig.(p) & Hazard ratio \\
\hline Age & 0.102 & 1.749 \\
Gleason_score & 0.029 & 0.528 \\
Location_of_metastasis & 0.738 & 0.904 \\
Disease_burden & 0.529 & 0.812 \\
\hline
\end{tabular}

Sig.: Parameters which may affect the survival (significant when the $p<0.05$ )

ment group. There was no statistically significant difference between the groups $(p=0.311)$. OS data are shown in Figure 1. A total of 15 patients in the chemotherapy group and 11 patients in the hormonal treatment group were alive at the time of data entry.

Median progression-free survival of the chemotherapy group was 5.6 months, while it was 9 months in the hormonal therapy group. There was statistically significant difference between the groups $(p=0.024)$. Progression-free survival data are shown in Figure 2. Nine patients in the hormonal therapy group and three patients in the chemotherapy group were still on their treatment at the time of data entry.

\section{Discussion}

It is not clear which agent should be used in the treatment of metastatic castration-resistant chemotherapynaive patients. Many options have been evaluated until today; docetaxel has become prominent as treatment of choice for chemotherapy, while abiraterone and en-

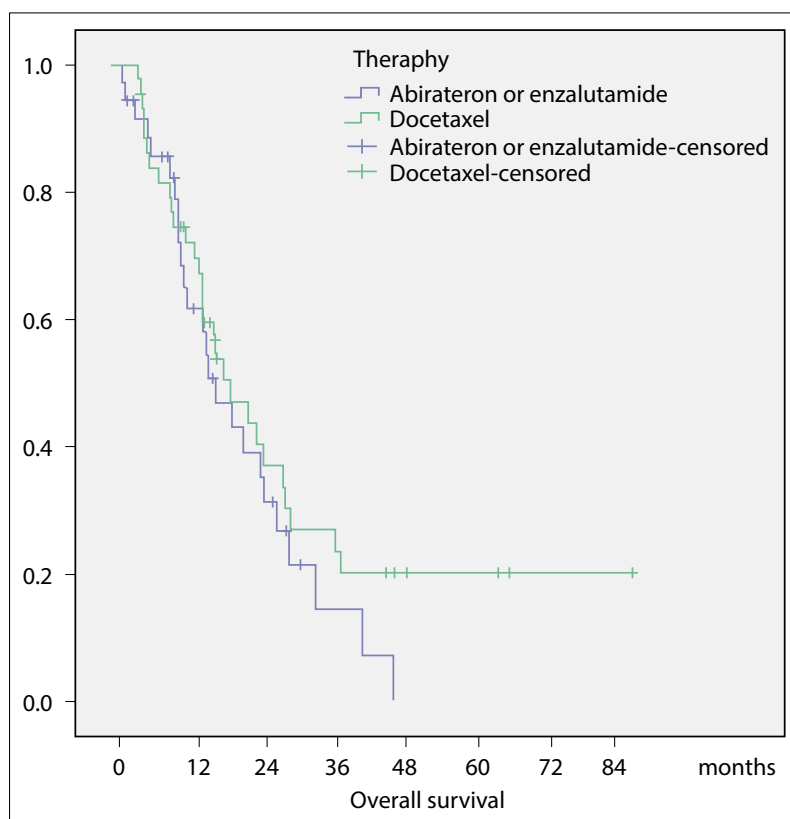

Fig. 1. Overall survival of patients.

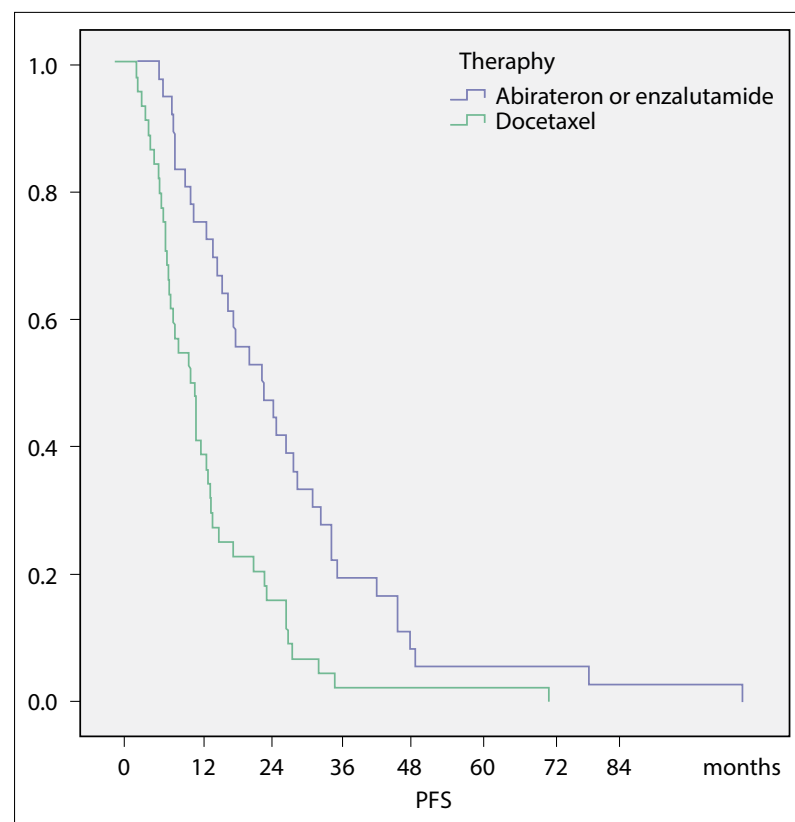

Fig. 2. Progression free survival of patients. PFS: Progression free survival.

zalutamide have become the hormonal treatments of choice. There is no prospective study on these agents; therefore, the treatment of these patients is up to the clinicians' decision.

When we examined the studies of these agents in CRPC patients, in a Phase 3 randomized study, where docetaxel, which was the first agent used, was com- 
pared with mitoxantrone, median survival in patients who received docetaxel was found to be 18.9 months. [4] In a study on abiraterone in this population, median survival was 34.7 months. [17] In another study on enzalutamide in CRPC patients, OS was found to be 35.3 months. [21]

In the present study, the OS of docetaxel was 18.66 months, and it was 16.26 months for abiraterone and enzalutamide which are hormonal therapies. In the numerical analysis of the results, the survival of the patients in the docetaxel arm was almost the same as the pivotal study.[4] However, this was not the case for the patients taking enzalutamide and abiraterone. The OS of these agents with an OS of 34 months in their pivotal study was 16.26 months in the present study. This may be due to the difference in the selection of patients. In pivotal studies of these agents, asymptomatic patients were especially included. As there were no such selection criteria in our study, it may have resulted in the difference. In Turkey, where the present study was conducted, abiraterone or enzalutamide can be used in patients who are not suitable for chemotherapy. Therefore, patients whose general condition is relatively worse receive hormonal therapies. The age parameter was significantly in favor of hormonal therapies and this result also promotes the condition. OS may be low in our study due to this disadvantage in patient selection. Poor survival in the pivotal study of docetaxel may result from not using other agents, which prolong life time, in sequential therapy.

In our study, progression-free survival was statistically significantly higher in the hormonal therapy arm than the group receiving chemotherapy. Despite the above-mentioned disadvantage in the selection of the patients, hormonal therapies were successful in progression-free survival compared to chemotherapy; however, the difference did not reflect on OS. This success in progression-free survival, on the other hand, obtained despite the limited number of patients. Therefore, based on the results of our study, hormonal therapies (abiraterone or enzalutamide) are more successful than docetaxel in castration-resistant metastatic chemotherapy-naive patients. Nevertheless, it is not possible to reach a definite conclusion based on the results of our retrospective study and larger prospective randomized controlled studies are needed on this subject.

\section{Conclusion}

There is no consensus on which drugs should be administered in chemotherapy-naive patients with metastatic castration-resistant prostate cancer. There was a statistical difference in progression-free survival in favor of hormonal therapies in our study. The difference did not reflect on OS and there was no difference between hormonal therapies and docetaxel. Heterogeneity in the selection of patients is considered to lead to this result; however, larger randomized controlled studies are needed to determine the most appropriate treatment in these patients.

Peer-review: Externally peer-reviewed.

Conflict of Interest: All authors declared no conflict of interest.

Ethics Committee Approval: The study was approved by the Manisa Celal Bayar University Faculty of Medicine Ethics Committee (No: 20.478.486, Date: 23/12/2020).

Financial Support: None declared.

Authorship contributions: Concept - S.Y.; Design - A.P.E.; Supervision - A.P.E.; Funding - None; Materials - A.P.E.; Data collection and/or processing - S.Y.; Data analysis and/ or interpretation - S.Y.; Literature search - S.Y.; Writing S.Y.; Critical review - S.Y.

\section{References}

1. Huggins C, Stevens RE Jr., Hodges CV. Studies on prostatic cancer: II. The effects of castration on advanced carcinoma of the prostate gland. Arch Surg 1941;43:209-23.

2. Armstrong AJ, Garrett-Mayer ES, Yang YC, de Wit R, Tannock IF, Eisenberger M. A contemporary prognostic nomogram for men with hormone-refractory metastatic prostate cancer: A TAX327 study analysis. Clin Cancer Res 2007;13(21):6396-403.

3. Armstrong AJ, Tannock IF, de Wit R, George DJ, Eisenberger $\mathrm{M}$, Halabi $\mathrm{S}$. The development of risk groups in men with metastatic castration-resistant prostate cancer based on risk factors for PSA decline and survival. Eur J Cancer 2010;46(3):517-25.

4. Tannock IF, de Wit R, Berry WR, Horti J, Pluzanska A, Chi KN, et al. Docetaxel plus prednisone or mitoxantrone plus prednisone for advanced prostate cancer. N Engl J Med 2004;351(15):1502-12.

5. Kelly WK, Halabi S, Carducci M, George D, Mahoney JF, Stadler WM, et al. Randomized, double-blind, placebo-controlled phase III trial comparing docetaxel and prednisone with or without bevacizumab in men with metastatic castration resistant prostate cancer: CALGB 90401. J Clin Oncol 2012;30(13):1534-40.

6. Tannock IF, Fizazi K, Ivanov S, Karlsson CT, Fléchon A, Skoneczna I, et al. Aflibercept versus placebo 
in combination with docetaxel and prednisone for treatment of men with metastatic castration-resistant prostate cancer (VENICE): A phase 3, double-blind randomized trial. Lancet Oncol 2013;14(8):760-8.

7. Petrylak DP, Vogelzang NJ, Budnik N, Wiechno PJ, Sternberg CN, Doner K, et al. Docetaxel and prednisone with or without lenalidomide in chemotherapy-naive patients with metastatic castration-resistant prostate cancer (MAINSAIL): A randomized, doubleblind, placebo-controlled phase 3 trial. Lancet Oncol 2015;16(4):417-25.

8. Araujo JC, Trudel GC, Saad F, Armstrong AJ, Yu EY, Bellmunt J, et al. Docetaxel and dasatinib or placebo in men with metastatic castration-resistant prostate cancer (READY): A randomized, double-blind phase 3 trial. Lancet Oncol 2013;14(13):1307-16.

9. Quinn DI, Tangen CM, Hussain M, Lara PN Jr., Goldkorn A, Moinpour CM, et al. Docetaxel and atrasentan versus docetaxel and placebo for men with advanced castration-resistant prostate cancer (SWOG S0421): A randomized phase 3 trial. Lancet Oncol 2013;14(9):893-900.

10. Fizazi K, Higano CS, Nelson JB, Gleave M, Miller K, Morris T, et al. Phase III, randomized, placebo-controlled study of docetaxel in combination with zibotentan in patients with metastatic castration-resistant prostate cancer. J Clin Oncol 2013;31(14):1740-7.

11. Scher HI, Jia X, Chi K, de Wit R, Berry WR, Albers $\mathrm{P}$, et al. Randomized, open-label phase III trial of docetaxel plus high-dose calcitriol versus docetaxel plus prednisone for patients with castration-resistant prostate cancer. J Clin Oncol 2011;29(16):2191-8.

12. Hahn NM, Marsh S, Fisher W, Langdon R, Zon R, Browning $M$, et al. Hoosier Oncology Group randomized phase II study of docetaxel, vinorelbine, and estramustine in combination in hormone-refractory prostate cancer with pharmacogenetic survival analysis. Clin Cancer Res 2006;12(20 Pt):6094-9.

13. Ferrero JM, Chamorey E, Oudard S, Dides S, Lesbats G, Cavaglione G, et al. Phase II trial evaluating a docetaxel-capecitabine combination as treatment for hormone-refractory prostate cancer. Cancer 2006;107(4):738-45.
14. Petrioli R, Paolelli L, Francini E, Manganelli A, Salvestrini F, Francini G. Weekly docetaxel and epirubicin in treatment of advanced hormone-refractory prostate cancer. Urology 2007;69(1):142-6.

15. Oudard S, Fizazi K, Sengeløv L, Daugaard G, Saad F, Hansen S, et al. Cabazitaxel versus docetaxel as firstline therapy for patients with metastatic castration-resistant prostate cancer: A randomized phase III TrialFIRSTANA. J Clin Oncol 2017;35(28):3189-97.

16. Rathkopf DE, Smith MR, de Bono JS, Logothetis CJ, Shore ND, de Souza P, et al. Updated interim efficacy analysis and long-term safety of abiraterone acetate in metastatic castration-resistant prostate cancer patients without prior chemotherapy (COU-AA-302). Eur Urol 2014;66(5):815-25.

17. Ryan CJ, Smith MR, Fizazi K, Saad F, Mulders PF, Sternberg $\mathrm{CN}$, et al. Abiraterone acetate plus prednisone versus placebo plus prednisone chemotherapynaive men with metastatic castration-resistant prostate cancer (COU-AA-302): Final overall survival analysis of a randomized, double-blind, placebo-controlled phase 3 study. Lancet Oncol 2015;16(2):152-60.

18. Ryan CJ, Smith MR, de Bono JS, Molina A, Logothetis CJ, de Souza P, Fizazi K, et al. Abiraterone in metastatic prostate cancer without previous chemotherapy. $\mathrm{N}$ Engl J Med 2013;368(2):138-48.

19. Beer TM, Armstrong AJ, Rathkopf DE, Loriot Y, Sternberg CN, Higano CS, et al. Enzalutamide in metastatic prostate cancer before chemotherapy. N Engl J Med 2014;371(5):424-33.

20. Loriot Y, Miller K, Sternberg CN, Fizazi K, De Bono JS, Chowdhury S, et al. Effect of enzalutamide on health-related quality of life, pain, and skeletal-related events in asymptomatic and minimally symptomatic, chemotherapy-naive patients with metastatic castration-resistant prostate cancer (PREVAIL): Results from a randomized, phase 3trial. Lancet Oncol 2015;16(5):509-21.

21. Evans CP, Higano CS, Keane T, Andriole G, Saad F, Iversen P, et al. The PREVAIL study: Primary outcomes by site and extent of baseline disease for enzalutamide-treated men with chemotherapy-naïve metastatic castration-resistant prostate cancer. Eur Urol 2016;70(4):675-83. 